\title{
The therapeutic effects of bee venom on some metabolic and antioxidant parameters associated with HFD-induced non-alcoholic fatty liver in rats
}

\author{
MERVAT Y. HANAFI ${ }^{1}$, EMAN L.M. ZAHER ${ }^{1}$, SOHA E.M. EL-ADELY ${ }^{1}$, AHMED SAKR $^{2}$, \\ AHMED H.M. GHOBASHI ${ }^{3}$, MADIHA H. HEMLY ${ }^{1}$, AMANI H. KAZEM ${ }^{4}$ and MAHER A. KAMEL ${ }^{1}$ \\ Departments of ${ }^{1}$ Biochemistry, ${ }^{2}$ Pharmacology, ${ }^{3}$ Genetics and ${ }^{4}$ Pathology, Medical Research Institute, \\ Alexandria University, Alexandria 21561, Egypt
}

Received November 3, 2017; Accepted March 15, 2018

DOI: $10.3892 /$ etm.2018.6028

\begin{abstract}
The present study was designed to investigate the therapeutic effects of bee venom (BV) on high-fat diet (HFD)-induced non-alcoholic fatty liver (NAFL) in rats at different levels. Histological manifestations, hepatic lipid content, liver function tests, glucose homeostasis, lipid abnormalities, adipocytokines, lipid peroxidation, disturbed glutathione and antioxidant enzymes systems and dysregulation of Nrf2 transcription factor were assessed. In the present study, the NAFL rats were subcutaneously treated with $\mathrm{BV}$ with different doses $(0.01,0.05,0.1 \mathrm{mg} / \mathrm{kg})$. The results indicated that BV treatment completely normalized the lipid profile values of NAFL rats. Fasting blood sugar, insulin level and homeostatic model assessment of insulin resistance significantly decreased. BV treated rats showed a significantly lower level of all liver enzymes and bilirubin. Moreover, BV treatment significantly increased the levels of active nuclear erythroid factor 2 like 2, glutathione (GSH) (total and reduced), GSH/glutathione disulphide ratio and activities of glutathione reductase, glutathione-S-transferase and glutathione peroxidase (total and Se-dependent). The level of tumor necrosis factor- $\alpha$ was reduced. Treatment showed correction of adiponectin level, and significant downregulation of hepatic triglycerides and cholesterol. At the histological level, BV improved the architecture of liver cells showing normal sinusoids. It may be concluded that BV may represent an interesting therapeutic alternative for the treatment of NAFL disease.
\end{abstract}

Correspondence to: Dr Maher A. Kamel, Department of Biochemistry, Medical Research Institute, Alexandria University, 165 El-Horreya, Alexandria 21561, Egypt

E-mail: maher.kamel@alexu.edu.eg

Key words: bee venom, non-alcoholic fatty liver, adiponectin, insulin resistance, dyslipidemia, $\mathrm{Nrf} 2$

\section{Introduction}

Non-alcoholic fatty liver diseases (NAFLD) encompass a spectrum of liver abnormalities, ranging from simple steatosis to steatohepatitis (non-alcoholic steatohepatitis; NASH) and fibrosis that may progress to cirrhosis and possibly hepatocarcinoma. NAFLD is often associated with insulin resistance, obesity, diabetes mellitus, hyperlipidemia, visceral adiposity and other cardiometabolic alterations (1).

During the pathogenesis of NAFLD, a crosstalk occurs between the liver and peripheral tissues such as the adipose tissue, skeletal muscle, and pancreas (2). Adipose tissue plays a pivotal role in the pathogenesis of NAFLD and the progression to steatohepatitis (3).

Day and James suggested the 'two-hit-theory' to provide a pathophysiological rationale to the progression of liver damage associated with NAFLD (4). The 'first hit' is excessive hepatocytes triglyceride (TGs) accumulation which may result from insulin resistance (IR) (5). The presumed factors initiating second hits are suggested to be oxidative stress and subsequent lipid peroxidation, pro-inflammatory cytokines [principally tumor necrosis factor (TNF)- $\alpha$ ], and dysregulation of adipocytokines derived from adipose (6).

Hepatocytes accumulation of reactive oxygen species (ROS); oxidative stress, could be responsible for further progression from steatosis to steatohepatitis and fibrosis. ROS-triggered lipid peroxidation of serum or mitochondrial membranes causes cell necrosis or induces apoptosis (7). The glutathione (GSH) system is the main cell redox regulator which represents the single largest source of reducing equivalents in the cell and accounts for approximately $90 \%$ of all cellular reducing equivalents. Therefore, the depletion of GSH could significantly affect the overall redox potential of the cell (8).

Nuclear erythroid factor 2 like 2 (Nrf2) is the master regulator of the antioxidant response to oxidative stresses. Nrf2 binds to its Antioxidant Response Element sequences ( $A R E$; $5^{\prime}-N T G A G / C N N N G C-3$ ') in its targets genes (9), thereby activating their transcription. Nrf2 activation represses the expression of the enzymes involved in fatty acids biosynthesis and uptake (10). It was documented that deletion of Nrf2 gene result in the accelerated induction of NAFLD and 
its progression to steatohepatitis (11) while Nrf2 activation attenuates the progression of NAFLD (12).

Despite an increasing understanding of the mechanisms of NAFLD pathogenesis, there are no drugs approved for it. Current treatments are directed towards improving the metabolic parameters which contribute to disease pathogenesis, such as weight loss and exercise, reducing IR and improving diabetic control.

Therapy currently undergoing evaluation is the honeybee (Apis mellifera) venom. Bee venom (BV) is known to be a very complex mixture of active peptides that includes melittin, phospholipase A2, apamin, adolapin and mast cell-degranulating peptide (13). Experimental studies on the biological activities of BV showed its anti-inflammatory and anticancer effects (14).

To our knowledge, there is no experimental or clinical data about the use of BV for the treatment of NAFLD. So, the present study is designed to evaluate the effect of BV treatment of NAFLD and interested in the change occurs in histological manifestations, glucose and lipid homeostasis, adipocytokines, redox status, oxidative stress and antioxidant enzyme systems.

\section{Materials and methods}

Animals. Fifty healthy male Wistar rats (weight, 100-120 g) were obtained from animal house facility at the Medical Research Institute. All rats were housed five per cage under controlled laboratory conditions and provided with commercial diet and tap water ad libitum. They were allowed one week acclimatization period before the initiation of the experiments. All persons involved in the study had completed animal care use and training. Experimental procedures, animal handling, sampling, and scarification followed the Guide for the Care and Use of Laboratory Animals, 8th edition (National Research Council, 2011) and were approved by 'Research Ethical Committee' of the Medical research institute, Alexandria University (Alexandria, Egypt). All efforts were made to minimize the rats suffering during the experimental period.

\section{Experimental design}

Induction of NAFL in rats using high-fat diet (HFD). In the present study, high fat-diet was used to induce NAFLD in rats according to the model proposed by Sene-Fiorese et al (15). The HFD consisted of commercial rat chow, peanuts, milk chocolate, and sweet biscuits in a proportion of $3: 2: 2: 1$. It was prepared by grinding well the commercial rat chow plus peanuts, and sweet biscuits. Then all the components of the HFD were blended in hot milk chocolate and left to cool and solidify. Rats were given the high fat diet daily for 14 weeks.

Experimental groups. Besides the normal control group $(\mathrm{n}=10$, Group I), the NAFL rats (Group II) were randomly allocated into 4 subgroups $(n=10$ each) and were kept on the same HFD till the end of the experimental period. Of which, group IIA represented the untreated NAFL animals (receiving saline), while those in groups IIB, IIC, and IID were treated day by day by subcutaneous injection with BV (VACSERA, Egypt) in a dose of $0.01,0.05$ and $0.1 \mathrm{mg} / \mathrm{kg}$, respectively.
The animals were killed by cervical dislocation on the next day following the last injection and $10 \mathrm{~h}$ fasting blood samples were collected by cardiac puncture and centrifuged ( $800 \mathrm{x} \mathrm{g}$, at $4^{\circ} \mathrm{C}$ for $20 \mathrm{~min}$ ) to separate the sera, which were used to assess the serum parameters. Also, liver of the rats was collected for biochemical and histological analysis to detect the progression of NAFLD.

Determination of serum parameters. The fasting serum glucose, AST, and ALT were assessed using Randox colorimetric reagent kits (Randox Laboratories, Dublin, Republic of Ireland) and insulin by an ELISA kit (Abnova, Jhongli, Taiwan). For lipid profile, the serum levels of TGs and total cholesterol (TC) were determined using Boehringer colorimetric kits (Mannheim, Germany), while HDL-C was determined according to the method described by Lopes-Virella et al (16); one aliquot of the serum was mixed with the precipitating reagent phosphotungstic acid and magnesium chloride then the cholesterol content was evaluated in the clear supernatant using the Boehringer kit. Finally, LDL-C was calculated according to the Friedewald equation: TC-(HDL-C+1/5 TGs) (17)

The homeostasis model assessment index for insulin resistance (HOMA-IR) was determined using the following formula: HOMA-IR=[fasting glucose $(\mathrm{mmol} / \mathrm{l}) \mathrm{x}$ fasting insulin $(\mu \mathrm{U} / \mathrm{ml})] / 22.5(18)$

The serum levels of TNF- $\alpha$ and adiponectin were analyzed using a commercially available ELISA kit (Biosource International, Camarillo, CA, USA).

Determination of liver parameters. Immediately after blood collection animals were euthanized using deep diethyl ether anesthesia and their livers were excised, homogenized, divided into aliquots and preserved at $-80^{\circ} \mathrm{C}$ until assay.

Assessment of tissue lipid contents. Hepatic lipids were extracted according to the method modified by Bligh and Dyer (19), where the chloroform layer, containing all lipids, was utilized to assay TGs and TC, as mentioned before.

Assessment of hepatic Nrf2. The Nrf2 activation and the ARE binding efficacy were evaluated in the liver nuclear extracts using a Trans AM Nrf2 kit (Active Motif, Carlsbad, CA, USA). Aliquots of $10 \mu \mathrm{g}$ protein of the nuclear extract were incubated with immobilized oligonucleotides containing the ARE consensus binding site (5'-GTCACAGTACTCAGCAGAATCTG-3') and the active form of $\mathrm{Nrf} 2$, that binds to the oligonucleotides, was detected using an anti-Nrf2 primary antibody after treating with the HRP-conjugated secondary antibody. Quantitative analysis of $\mathrm{Nrf} 2$ ( $\mu \mathrm{g} / \mathrm{mg}$ nuclear protein) was performed by measuring the chromogen formed as a result of the specific activity of the transcription factor in the nuclear extracts using a plate reader at $450 \mathrm{~nm}(20)$.

Assessment of lipid peroxidation. The end products of lipid peroxidation were determined as thiobarbituric acid reactive substance (TBARS) assay (21). In this assay, the malondialdehyde is heated with thiobarbituric acid (TBA) at low pH to produce a pink chromogen with a maximum absorbance at $532 \mathrm{~nm}$. 
Table I. Serum ALT, AST, GGT activities, and total Bil in control rats and NAFL rats untreated and treated with different doses of bee venom.

\begin{tabular}{|c|c|c|c|c|c|}
\hline \multirow[b]{3}{*}{ Parameter } & \multirow[b]{3}{*}{$\begin{array}{l}\text { Group I (control) } \\
\qquad(\mathrm{n}=10)\end{array}$} & \multicolumn{4}{|c|}{ Group II (NAFL) } \\
\hline & & \multirow[b]{2}{*}{$\begin{array}{l}\text { Untreated } \\
(\mathrm{n}=10)\end{array}$} & \multicolumn{3}{|c|}{ Bee venom treated } \\
\hline & & & $\begin{array}{c}0.01 \mathrm{mg} / \mathrm{kg} \\
\quad(\mathrm{n}=10)\end{array}$ & $\begin{array}{c}0.05 \mathrm{mg} / \mathrm{kg} \\
(\mathrm{n}=10)\end{array}$ & $\begin{array}{l}0.1 \mathrm{mg} / \mathrm{kg} \\
(\mathrm{n}=10)\end{array}$ \\
\hline ALT (U/l) & $46.6 \pm 3.40$ & $67.85 \pm 8.73^{\mathrm{a}}$ & $41.85 \pm 12.11^{\mathrm{b}}$ & $40.45 \pm 9.35^{\mathrm{b}}$ & $39.65 \pm 10.00^{\mathrm{b}}$ \\
\hline $\operatorname{AST}(\mathrm{U} / \mathrm{l})$ & $128.2 \pm 23.65$ & $204.70 \pm 32.00^{\mathrm{a}}$ & $121.20 \pm 22.80^{\mathrm{b}}$ & $122.90 \pm 10.54^{\mathrm{b}}$ & $122.60 \pm 18.55^{\mathrm{b}}$ \\
\hline GGT (U/1) & $13.3 \pm 2.00$ & $51.50 \pm 3.60^{\mathrm{a}}$ & $43.60 \pm 10.38^{\mathrm{a}}$ & $38.90 \pm 14.19^{\mathrm{a}, \mathrm{b}}$ & $36.90 \pm 6.51^{\mathrm{a}, \mathrm{b}}$ \\
\hline Bil (mg/dl) & $0.54 \pm 0.30$ & $1.67 \pm 0.22^{\mathrm{a}}$ & $1.04 \pm 0.18^{\mathrm{a}, \mathrm{b}}$ & $1.14 \pm 0.21^{\mathrm{a}, \mathrm{b}}$ & $0.93 \pm 0.12^{\mathrm{a}, \mathrm{b}}$ \\
\hline
\end{tabular}

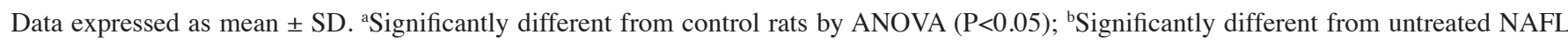
rats by ANOVA $(\mathrm{P}<0.05)$. ALT, alanine aminotransferase; AST, aspartate aminotransferase; GGT, gamma-glutamyltransferase; Bil, bilirubin; NAFL, non-alcoholic fatty liver; ANOVA, one-way analysis of variance.

Assay of reduced GSH and glutathione disulphide (GSSG). GSH and GSSG were assayed using the method of Griffith (22) which depends on the oxidation of GSH by 5,5'-dithiobis-(2-nitrobenzoic acid) (DTNB) to yield GSSG and 5-thio-2-nitrobenzoic acid (TNB). Oxidized GSSG is reduced enzymatically by the action of glutathione reductase (GR) and NADPH to regenerate GSH. The rate of TNB formation is monitored at $412 \mathrm{~nm}$ and is proportional to the sum of GSH and GSSG present in the sample.

Assay of GSH metabolizing enzymes. The activity of GR was assayed by the method of Smith et al (23). Which based on the reduction of DTNB by GSH produced by GR which results in the release of TNB that monitored spectrophotometrically at $412 \mathrm{~nm}$. One unit of the enzyme activity is defined as the amount of the enzyme that catalyzes the formation of $1 \mu \mathrm{mol}$ of TNB per minute.

The activity of glutathione-S-transferase (GST) was determined by the method of Habig et al (24). The GST catalyzed the conjugation of GSH with 1-chloro-2,4-dinitrobenzene (CDNB) is measured spectrophotometrically at $340 \mathrm{~nm}$. One unite of the enzyme activity is defined as the amount of enzyme that catalyzes the formation of $1 \mu \mathrm{mol} \mathrm{S}$-conjugate per minute under the assay conditions.

The total glutathione peroxidase (GPx) activities were determined by the method of Flohé and Günzler (25). This method is based on monitoring the generation of GSH from GSSG by the action of GR and NADPH. Total GPx (tGPx) activity was measured using cumene hydroperoxide as substrate whereas Se-dependent GPx (sGPx) activity was measured using $\mathrm{H}_{2} \mathrm{O}_{2}$ as substrate. Non-selenium-dependant GPx (nsGPx) activity was calculated as the difference between the total GPx and sGPx.

Histopathological study. Liver tissue specimens from each studied groups were fixed in $10 \%$ neutral buffered formalin then washed in running water, dehydrated in ascending series of ethyl alcohol, cleared in xylem and embedded in paraffin wax. Section of $4 \mu \mathrm{m}$ thick was cut by microtome and stained with hematoxylin and eosin stain (H\&E) for histopathological investigations.
Statistical analysis. All data are presented as mean \pm SD. A one-way analysis of variance (ANOVA) was performed on each variable followed by Tukey post-hoc test. The Kolmogorov-Smirnov test was used to study the normal distribution of the studied parameters. $\mathrm{P}<0.05$ was considered to indicate a statistically significant difference. All statistical analyses were performed using SPSS statistical software version 18 (SPSS, Inc., Chicago, IL, USA).

\section{Results}

Liver function test. The untreated NAFL rats showed significantly higher serum activities of ALT, AST, GGT and higher serum level of bilirubin compared to control rats (Table I). NAFL rats treated with BV show significantly lower levels of all function liver tests compared untreated NAFL rats in dose dependent manner. However, the activity of GGT and level of bilirubin were significantly lower in treated rats compared to untreated NAFL rats, but their levels still higher than control value (Table I).

Glucose homeostasis parameters. The untreated NAFL rats showed significantly higher serum level of fasting blood glucose and insulin compared to control rats while the NAFL rats treated with $\mathrm{BV}$ showed the significantly lower value of FBG and insulin compared to untreated NAFL rats in dose dependent manner (Table II).

The insulin resistance index calculated by the HOMA model (HOMA-IR) indicated that NAFL rats treated with BV showed the significantly lower value of HOMA-IRI compared to untreated NAFL rats in dose dependent manner (Table II). Although the level of fasting insulin and HOMA-IRI were significantly lower in the treated NAFL rats compared to untreated NAFL rats, their levels were still higher in treated NAFL rats compared to control rats (Table II).

Lipid profile. The untreated NAFL rats showed significantly higher level of TG, TC, and LDL-C, while showed significant lower level of HDL-C (Table II). NAFL rats treated with BV showed significantly lower levels of TG, TC and LDL-C 
Table II. Serum glucose homeostasis parameters, lipid profile and hepatic trigycerides and cholesterol contents in control rats and NAFL rats untreated and treated with different doses of bee venom.

\begin{tabular}{|c|c|c|c|c|c|}
\hline \multirow[b]{3}{*}{ Parameter } & \multirow[b]{3}{*}{$\begin{array}{l}\text { Group I (Control) } \\
\qquad(\mathrm{n}=10)\end{array}$} & \multicolumn{4}{|c|}{ Group II (NAFL) } \\
\hline & & \multirow[b]{2}{*}{$\begin{array}{l}\text { Untreated } \\
(\mathrm{n}=10)\end{array}$} & \multicolumn{3}{|c|}{ Bee venom treated } \\
\hline & & & $\begin{array}{c}0.01 \mathrm{mg} / \mathrm{kg} \\
\quad(\mathrm{n}=10)\end{array}$ & $\begin{array}{c}0.05 \mathrm{mg} / \mathrm{kg} \\
\quad(\mathrm{n}=10)\end{array}$ & $\begin{array}{l}0.1 \mathrm{mg} / \mathrm{kg} \\
(\mathrm{n}=10)\end{array}$ \\
\hline FBG (mg/dl) & $74.6 \pm 11.94$ & $116.80 \pm 8.57^{\mathrm{a}}$ & $71.90 \pm 9.55^{\mathrm{b}}$ & $72.20 \pm 13.59^{b}$ & $67.20 \pm 7.55^{\mathrm{b}}$ \\
\hline Insulin $(\mu \mathrm{IU} / \mathrm{ml})$ & $3.60 \pm 1.34$ & $12.20 \pm 0.61^{\mathrm{a}}$ & $9.96 \pm 1.50^{\mathrm{a}, \mathrm{b}}$ & $10.68 \pm 1.51^{\mathrm{a}, \mathrm{b}}$ & $9.92 \pm 0.34^{\mathrm{a}, \mathrm{b}}$ \\
\hline HOMA-IRI & $0.66 \pm 0.28$ & $3.52 \pm 0.36^{\mathrm{a}}$ & $1.77 \pm 0.42^{\mathrm{a}, \mathrm{b}}$ & $1.90 \pm 0.48^{\mathrm{a}, \mathrm{b}}$ & $1.65 \pm 0.23^{\mathrm{a}, \mathrm{b}}$ \\
\hline TGs (mg/dl) & $35.6 \pm 8.49$ & $57.90 \pm 13.30^{\mathrm{a}}$ & $45.30 \pm 7.12$ & $42.20 \pm 15.08$ & $38.80 \pm 17.74^{\mathrm{b}}$ \\
\hline $\mathrm{TC}(\mathrm{mg} / \mathrm{dl})$ & $147.2 \pm 27.67$ & $174.60 \pm 24.64^{\mathrm{a}}$ & $129.0 \pm 13.33^{\mathrm{b}}$ & $128.50 \pm 11.27^{\mathrm{b}}$ & $125.50 \pm 21.70^{\mathrm{b}}$ \\
\hline HDL-C (mg/dl) & $43.4 \pm 7.07$ & $32.23 \pm 1.86^{\mathrm{a}}$ & $50.69 \pm 7.01^{\mathrm{b}}$ & $52.60 \pm 10.85^{\mathrm{b}}$ & $54.77 \pm 12.0^{\mathrm{a}, \mathrm{b}}$ \\
\hline LDL-C (mg/dl) & $96.6 \pm 29.42$ & $130.8 \pm 26.17^{\mathrm{a}}$ & $69.3 \pm 15.77^{\mathrm{a}, \mathrm{b}}$ & $67.5 \pm 15.69^{\mathrm{a}, \mathrm{b}}$ & $63.0 \pm 12.12^{\mathrm{a}, \mathrm{b}}$ \\
\hline Hepatic TGs (mg/g liver) & $33.9 \pm 8.56$ & $124.1 \pm 14.25^{\mathrm{a}}$ & $80.6 \pm 8.69^{a, b}$ & $69.5 \pm 12.19^{\mathrm{a}, \mathrm{b}}$ & $56.3 \pm 8.06^{\mathrm{a}, \mathrm{b}}$ \\
\hline Hepatic TC (mg/g liver) & $15.71 \pm 1.96$ & $38.19 \pm 5.50^{\mathrm{a}}$ & $29.46 \pm 3.20^{\mathrm{a}, \mathrm{b}}$ & $23.54 \pm 3.13^{\mathrm{a}, \mathrm{b}}$ & $18.87 \pm 2.63^{\mathrm{a}, \mathrm{b}}$ \\
\hline
\end{tabular}

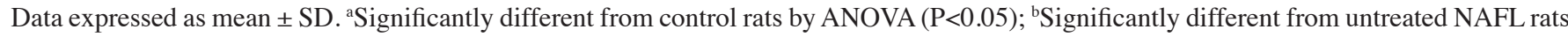
by ANOVA $(\mathrm{P}<0.05)$. ANOVA, one-way analysis of variance; NAFL, non-alcoholic fatty liver; HOMA-IRI, homeostasis model assessment index for insulin resistance; TGs, triglycerides; TC, total cholesterol.

Table III. The serum and hepatic levels of glutathione system in control rats and NAFL rats untreated and treated with different doses of bee venom.

\begin{tabular}{|c|c|c|c|c|c|}
\hline \multirow[b]{3}{*}{ Parameter } & \multirow[b]{3}{*}{$\begin{array}{l}\text { Group I (control) } \\
\qquad(\mathrm{n}=10)\end{array}$} & \multicolumn{4}{|c|}{ Group II (NAFL) } \\
\hline & & \multirow[b]{2}{*}{$\begin{array}{l}\text { Untreated } \\
(\mathrm{n}=10)\end{array}$} & \multicolumn{3}{|c|}{ Bee venom treated } \\
\hline & & & $\begin{array}{c}0.01 \mathrm{mg} / \mathrm{kg} \\
(\mathrm{n}=10)\end{array}$ & $\begin{array}{c}0.05 \mathrm{mg} / \mathrm{kg} \\
(\mathrm{n}=10)\end{array}$ & $\begin{array}{l}0.1 \mathrm{mg} / \mathrm{kg} \\
\quad(\mathrm{n}=10)\end{array}$ \\
\hline Serum tGSH $(\mu \mathrm{mol} / \mathrm{l})$ & $83.61 \pm 5.34$ & $64.84 \pm 8.71^{\mathrm{a}}$ & $65.09 \pm 10.57^{\mathrm{a}}$ & $69.65 \pm 16.09^{\mathrm{a}}$ & $69.37 \pm 7.37^{\mathrm{a}}$ \\
\hline Serum GSH $(\mu \mathrm{mol} / \mathrm{l})$ & $73.95 \pm 4.84$ & $43.58 \pm 10.85^{\mathrm{a}}$ & $49.91 \pm 8.89^{a}$ & $54.74 \pm 17.64^{\mathrm{a}}$ & $56.30 \pm 9.72^{\mathrm{a}}$ \\
\hline Serum GSSG $(\mu \mathrm{mol} / 1)$ & $4.82 \pm 1.08$ & $10.63 \pm 1.50^{\mathrm{a}}$ & $7.59 \pm 2.11^{\mathrm{a}, \mathrm{b}}$ & $7.47 \pm 1.27^{\mathrm{a}, \mathrm{b}}$ & $6.55 \pm 1.87^{\mathrm{b}}$ \\
\hline Serum GSH/GSSG & $15.93 \pm 3.19$ & $4.29 \pm 1.67^{\mathrm{a}}$ & $7.04 \pm 2.17^{\mathrm{a}}$ & $7.72 \pm 3.10^{\mathrm{a}}$ & $9.55 \pm 4.07^{\mathrm{a}, \mathrm{b}}$ \\
\hline Hepatic tGSH ( $\mu \mathrm{mol} / \mathrm{g}$ liver) & $1.92 \pm 0.20$ & $1.03 \pm 0.27^{\mathrm{a}}$ & $1.17 \pm 0.35^{\mathrm{a}}$ & $1.27 \pm 0.50^{\mathrm{a}}$ & $1.42 \pm 0.39^{\mathrm{a}}$ \\
\hline Hepatic GSH ( $\mu \mathrm{mol} / \mathrm{g}$ liver $)$ & $1.78 \pm 0.27$ & $0.65 \pm 0.30^{\mathrm{a}}$ & $0.89 \pm 0.35^{\mathrm{a}}$ & $1.08 \pm 0.46^{\mathrm{a}}$ & $1.14 \pm 0.41^{\mathrm{a}, \mathrm{b}}$ \\
\hline Hepatic GSSG ( $\mu \mathrm{mol} / \mathrm{g}$ liver$)$ & $0.07 \pm 0.01$ & $0.19 \pm 0.04^{\mathrm{a}}$ & $0.15 \pm 0.07^{\mathrm{a}}$ & $0.14 \pm 0.04^{\mathrm{a}}$ & $0.14 \pm 0.05^{\mathrm{a}}$ \\
\hline Hepatic GSH/GSSG & $27.45 \pm 5.61$ & $3.74 \pm 1.97^{\mathrm{a}}$ & $7.09 \pm 4.20^{\mathrm{a}}$ & $8.69 \pm 4.56^{\mathrm{a}}$ & $10.87 \pm 8.62^{\mathrm{a}, \mathrm{b}}$ \\
\hline
\end{tabular}

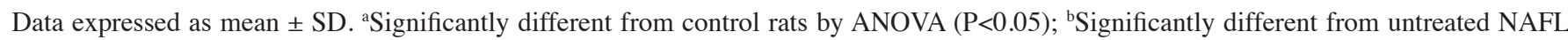
rats by ANOVA $(\mathrm{P}<0.05)$. ANOVA, one-way analysis of variance; NAFL, non-alcoholic fatty liver; GSH, reduced glutathione; tGSH, total glutathione; GSSG, glutathione disulphide.

compared to untreated NAFL rats in dose dependent manner. Furthermore, the level of HDL-C showed dose dependent increase in NAFL rats treated with BV as the level of HDL-C level showed significantly high level compared to untreated NAFL rats even with the lowest dose and the treated NAFL rats had also higher HDL-C level than control rat at BV doses of 0.05 and $0.1 \mathrm{mg} / \mathrm{kg}$ (Table II).

Hepatic lipid contents. The hepatic tissues of untreated NAFL rats showed greatly elevated contents of TGs (by approximately
266\%) and cholesterol (by approximately 143\%) compared to the hepatic tissues of control rats. The NAFL rats treated with BV showed significant downregulation of hepatic contents of TGs and cholesterol in a dose-dependent manner. However, even with the highest dose used $(0.1 \mathrm{mg} / \mathrm{kg})$ the hepatic contents of TGs and cholesterol still were higher than control values by approximately 66 and $12.7 \%$, respectively (Table II).

\section{Antioxidant parameters}

GSH system 


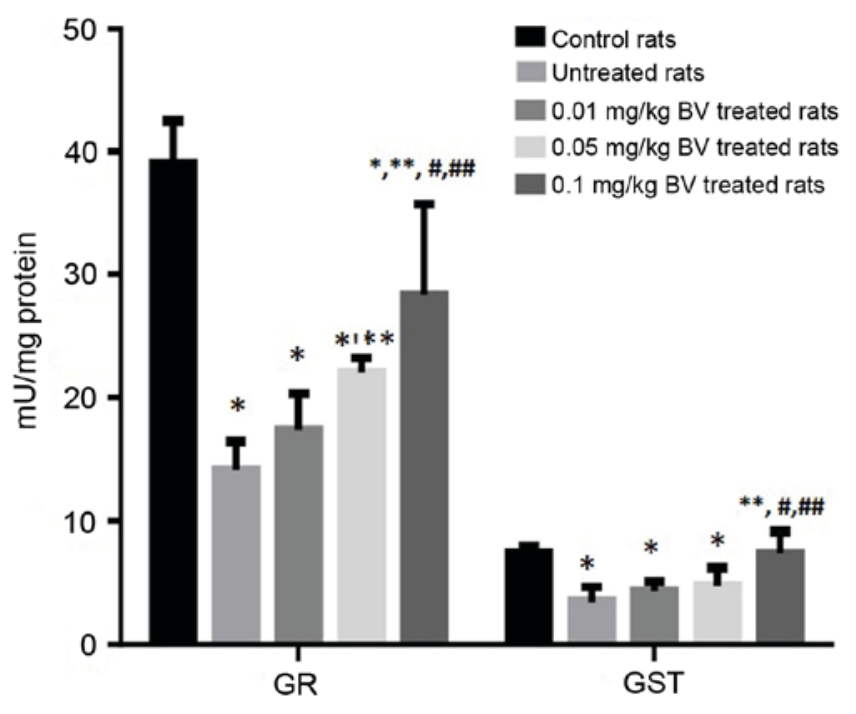

Figure 1. Hepatic GST and GR activities in control and NAFL rats untreated and treated with different doses of BV. "Significantly different from control; ** significantly different from untreated NAFL rats; "significantly different from $0.01 \mathrm{mg} / \mathrm{kg}$ treated NAFL rats; ${ }^{\# \#}$ significantly different from $0.05 \mathrm{mg} / \mathrm{kg}$ treated NAFL rats by ANOVA; $\mathrm{P}<0.05$. BV, bee venom; GR, glutathione reductase; GST, glutathione-S-transferase; NAFL, non-alcoholic fatty liver; ANOVA, one-way analysis of variance.

Serum and hepatic GSH system (tGSH, GSH, GSSG and GSH/GSSG ratio). The untreated NAFL rats showed significantly lower serum levels of tGSH and GSH compared to control rats by approximately 22.4 and $41.1 \%$, respectively. While the hepatic levels of tGSH and GSH of untreated NAFL rats showed more decline by approximately 46.4 and $63.5 \%$, respectively. In contrast, the serum and hepatic levels of GSSG were significantly higher in NAFL rats by approximately 120.5 and $171.4 \%$, respectively, compared to control rats. Consequently, the serum and hepatic GSH/GSSG ratio was significantly lower in the NAFL rats by 73 and $86.4 \%$, respectively (Table III).

The NAFL rats treated with BV showed no significant correction in the levels of serum and hepatic total GSH or serum reduced GSH while they showed a dose-dependent increase in the level of reduced hepatic GSH which becomes significant at the highest dose of BV $(0.1 \mathrm{mg} / \mathrm{kg})$. While they showed a significant dose-dependent decline in the serum level of oxidized glutathione (GSSG). On the other hand, the hepatic level of GSSG showed no significant changes in the NAFL rats treated with different doses of BV (Table III).

Regarding GSH/GSSG ratio, only the NAFL rats treated with the highest dose of BV $(0.1 \mathrm{mg} / \mathrm{kg})$ showed significantly higher value than the untreated NAFL rats (Table III).

GSH metabolizing enzymes; GR, GST, and GPxs (tGPx, sGPx and $n s G P x)$. The untreated NAFL rats showed significantly lower activities of GR and GST compared to control rats by approximately 63.9 and $53.3 \%$; respectively, while only the highest dose of BV $(0.1 \mathrm{mg} / \mathrm{kg})$ was able to normalize GST activity (Fig. 1). Moreover, significantly lower activities of tGPx and sGPx were noticed in untreated NAFL rats compared to control rats by approximately 28 and $31 \%$, respectively. In contrast, the untreated NAFL rats showed a non-significant

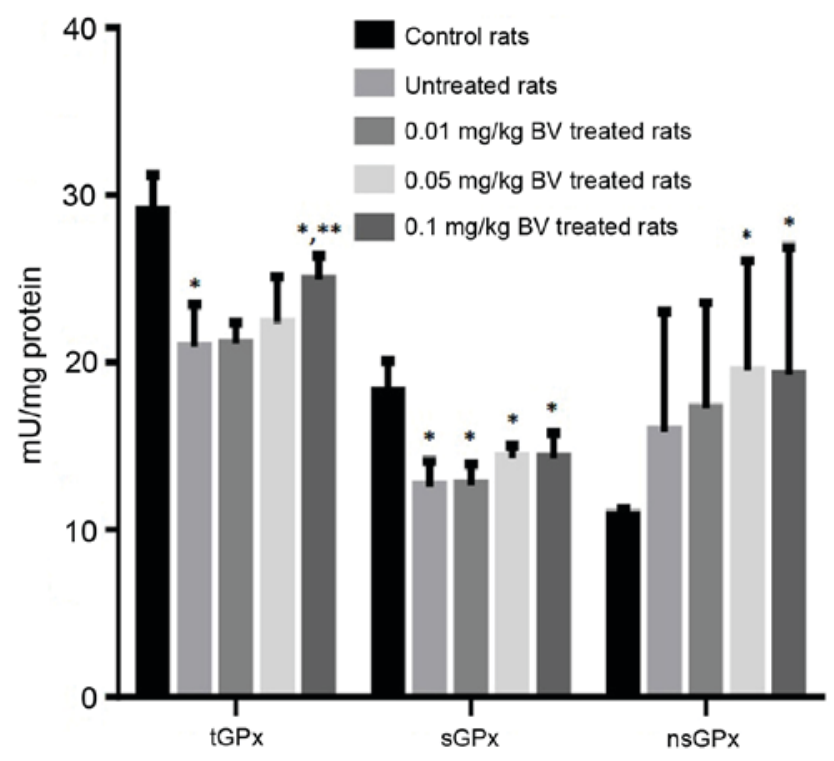

Figure 2. Hepatic activities of glutathione peroxidases, tGPx, sGPx and nsGPx in control and NAFL rats untreated and treated with different doses of BV. *Significantly different from control; ** significantly different from untreated NAFL rats, by ANOVA; P<0.05. BV, bee venom; tGPx, total GPx; sGPx, se-dependent GPx; nsGPx, non-selenium-dependant GPx; GPx, glutathione peroxidase; ANOVA, one-way analysis of variance.

increase in the activity of the nsGPx by approximately $46.3 \%$ compared to control rats (Fig. 2). The treatment of NAFL rats with BV cause significant elevation of all GSH metabolizing enzymes (GR, GST, tGPx, sGPx and nsGPx) in a dose-dependent manner (Figs. 2 and 3).

Hepatic nuclear erythroid related factor 2 (Nrf2). The hepatic level of Nrf2 greatly declined in the untreated NAFL rats by approximately $65.8 \%$ compared to control rats. The NAFL rats treated with BV showed a dose-dependent elevation of Nrf2 compared to the untreated rats with the significant elevation was observed at the highest dose $(0.1 \mathrm{mg} / \mathrm{kg})$ however, the level still lower than control value (Fig. 3).

Lipid peroxidation index (MDA assayed as TBARS). The untreated NAFL rats showed great elevation in the level of MDA by approximately $233 \%$ compared to control rats. The NAFL rats treated with BV showed significantly lower levels of MDA compared to untreated rats in a dose-dependent manner, however, its level still higher than control value (Fig. 4).

Adipocytokines levels. The untreated NAFL rats showed significantly lower serum level of adiponectin by approximately half compared to the control rats, while the untreated rats showed significantly higher serum level of TNF- $\alpha$ by approximately $100 \%$ compared to the control rats. The treatment of NAFL rats with BV at the dose of 0.01 and $0.05 \mathrm{mg} / \mathrm{kg}$ was responsible for the complete normalization of the adiponectin level. On the other hand, the treatment of NAFL rats with BV showed the slightly lower level of TNF- $\alpha$ compared to untreated rats even with the highest dose (Fig. 5).

Histopathological examination. Liver sections of normal control rats showed normal plates of hepatocytes radiating 


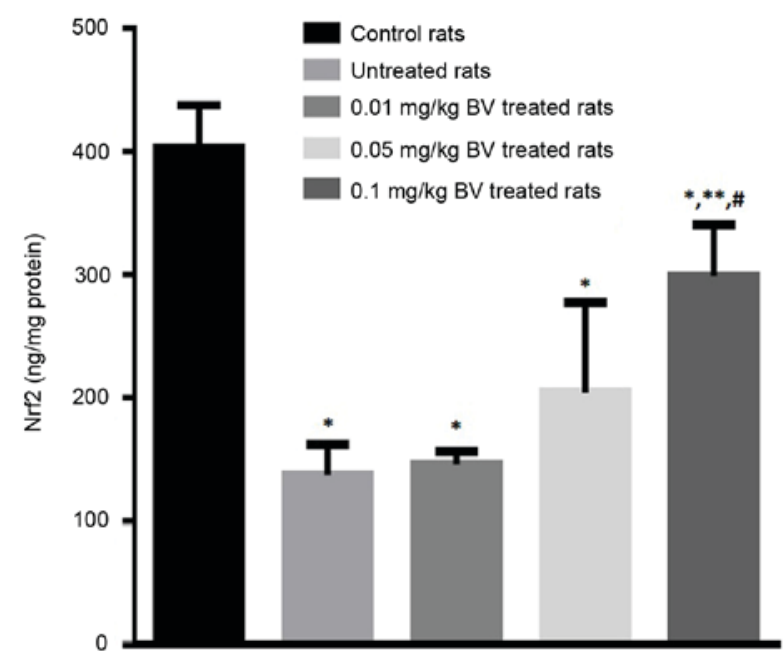

Figure 3. Hepatic Nrf2 contents in control and NAFL rats untreated and treated with different doses of BV. "Significantly different from control; ${ }^{* *}$ significantly different from untreated NAFL rats; ${ }^{*}$ significantly different from $0.01 \mathrm{mg} / \mathrm{kg}$ treated NAFL rats by ANOVA; $\mathrm{P}<0.05$. BV, bee venom; Nrf2, nuclear erythroid factor 2 like 2; NAFL, non-alcoholic fatty liver.

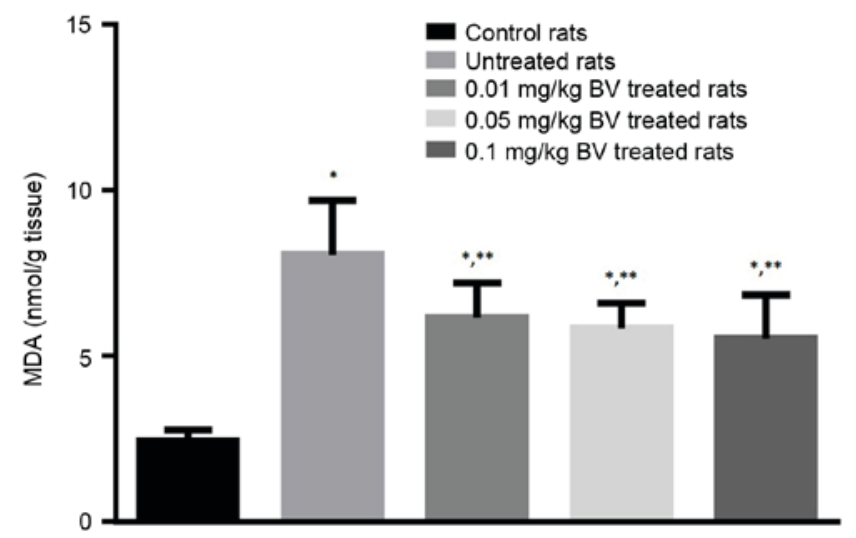

Figure 4. Hepatic MDA contents in control and NAFL rats untreated and treated with different doses of BV. "Significantly different from control; ${ }^{* *}$ significantly different from untreated NAFL rats by ANOVA; $\mathrm{P}<0.05$. BV, bee venom; NAFL, non-alcoholic fatty liver; ANOVA, one-way analysis of variance.

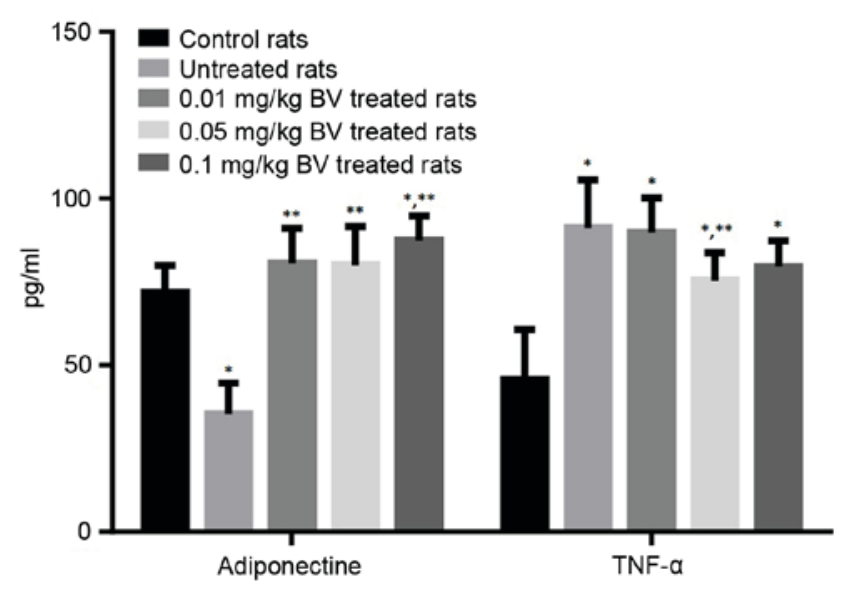

Figure 5. Serum levels of adiponectin and TNF- $\alpha$ in control and NAFL rats untreated and treated with different doses of BV. "significantly different from control; ** significant different from untreated NAFL rats by ANOVA; $\mathrm{P}<0.05$. $\mathrm{BV}$, bee venom; TNF- $\alpha$, tumor necrosis factor- $\alpha$; NAFL, non-alcoholic fatty liver; ANOVA, one-way analysis of variance.

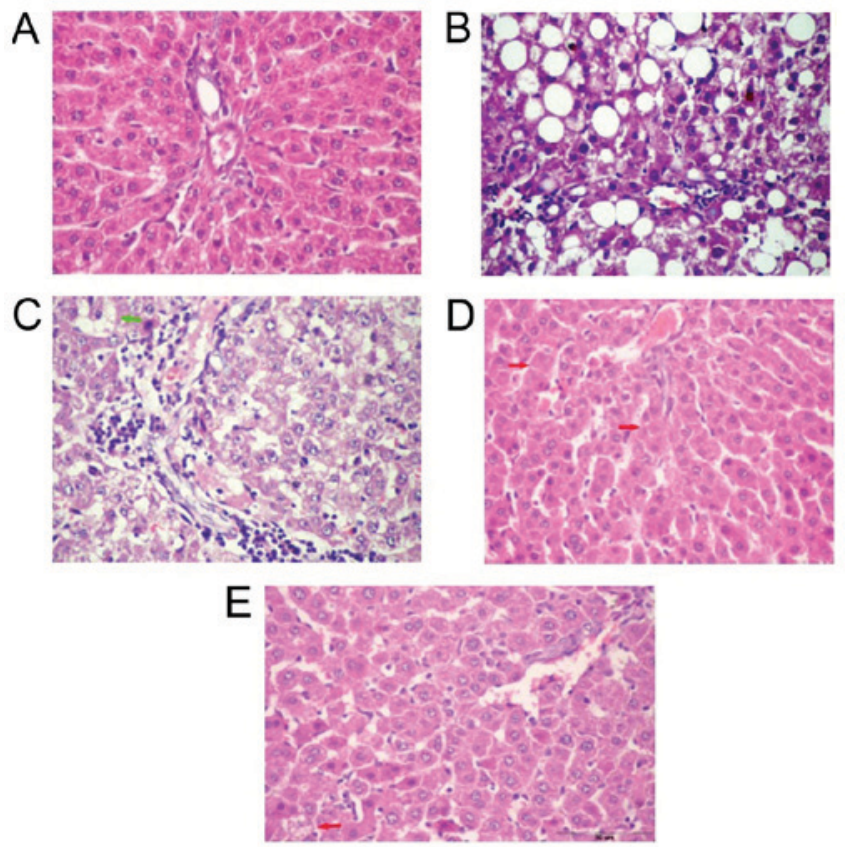

Figure 6. H\&E stain of liver section of control rats (A) showing normal hepatocytes with central vein, sinusoids and Kupffer cells. NAFL liver section (B) shows congested central vein, dilated sinusoids, necrosis, microsteatosis and macrosteatosis. Liver section of NAFL rat treated with BV in a dose of $0.01 \mathrm{mg} / \mathrm{kg}(\mathrm{C})$ and $0.05 \mathrm{mg} / \mathrm{kg}$ (D) showing mild microvesicular steatosis of hepatocytes with showing focal coagulative necrosis (arrows) while, $0.1 \mathrm{mg} / \mathrm{kg}$ (E) showing normal sinusoids and normal architecture with a single cell showing microvesicular steatosis. Magnification, x400. BV, bee venom; NAFL, non-alcoholic fatty liver; $\mathrm{H} \& \mathrm{E}$, hematoxylin and eosin.

from the central vein. The majority of hepatocytes are mononucleated and some hepatocytes are binucleated (Fig. 6A). The liver section of untreated NAFL rats showed zonal degeneration; congested central and portal veins impacted with haemolysed blood, increased inflammatory cellular infiltration in portal area, dilated sinusoids, necrosis, micro and macrosteatosis (Fig. 6B). Liver sections of NAFL rat treated with BV $(0.01 \mathrm{mg} / \mathrm{kg})$ showed decreased inflammatory cellular infiltration in a portal area with congested portal vein and fatty degeneration in some hepatocytes as compared with NAFL group (Fig. 6C). The treatment with BV in a dose of $0.05 \mathrm{mg} / \mathrm{kg}$ showed minimal congestion in central vein and in sinusoids and increased eosinophilic stain in some hepatocytes and a little number of fatty degeneration and apoptotic figures (Fig. 6D). With the highest dose $(0.1 \mathrm{mg} / \mathrm{kg})$, the liver sections showed normal sinusoids with minimal inflammatory cellular infiltration compared to control liver (Fig. 6E).

\section{Discussion}

The present study is designed to evaluate the effect of BV treatment of NAFLD and interested in the change occurs in histological manifestations, glucose and lipid homeostasis, adipocytokines, redox status, oxidative stress and antioxidant enzyme systems. NAFL rats demonstrated significant hepatic accumulation of TGs, cholesterol. Also, the activities of serum transaminases; AST, ALT, and GGT were significantly elevated. NAFL rats showed higher bilirubin value. These abnormalities of liver function tests indicated significant hepatocytes 
inflammation, damage, and necrosis as confirmed in the histological results. At the glucose homeostasis level, NAFL rats showed a significant elevation in fasting blood glucose, insulin and HOMA-insulin resistance index that indicated a state of insulin resistance which represents the first hit for hepatic fat accumulation and steatosis according to the two hit theory (4).

The disturbed glucose homeostasis parameters in NAFL rats were associated with significant abnormalities in the lipid profile parameters; serum levels of TGs, total cholesterol and LDL-cholesterol were significantly higher while HDL-cholesterol was lower compared to control rats. This condition is commonly referred to as dyslipidemia (26). The observed impairments in carbohydrate and lipid metabolism were associated with a significant disruption in adipocytokine production. The results indicated a significant reduction in the serum level of adiponectin while the TNF- $\alpha$ level significantly increased compared to control rats. The hypoadiponectinemia may be a cause of obesity and adipose tissue-specific insulin resistance (27). The action of TNF- $\alpha$ is intimately related to the upregulation of intracellular generation of ROS and then of oxidative stress $(28,29)$. Taken together, these findings indicate that TNF- $\alpha$ and adiponectin are critical factors for. occurrence and progression of NAFLD/NASH. Also, NAFL rats showed enhanced hepatic lipid peroxidation as indicated by the higher level of malondialdehyde. Even in the basal (low-fat) state, hepatocytes produce large amounts of ROS as indicated by the detectable level of MDA in control rats (30). This large basal ROS formation is further enhanced in steatotic livers (31). The insulin resistance, accumulation of fats in hepatocytes, and induction of inflammatory cytokines may participate in the induction of oxidative stress (32).

The present study indicated a significant decline in the active nuclear Nrf2 in untreated NAFL rats. Nrf2 is a transcription factor that is the master inducer of the endogenous antioxidant response to endogenous and exogenous oxidative stress (33). In support of the previous hypothesis, the present study confirmed depletion of the serum and hepatic total and reduced glutathione (GSH) and a decline in the redox ratio (GSH/GSSG) in NAFL rats. These disturbances in GSH system were associated with significant inhibition in the activities of GSH metabolizing enzymes; GR and GST. Also, the activities of total and sGPx were significantly inhibited in NAFL rats.

Many of BV components are being also used in experimental pharmacology (34). From the results of the present study, it was clearly demonstrated that BV treatment significantly improved hepatic function parameters and hepatic TGs and cholesterol contents although a few of these contents remained higher than normal control values. BV effect on insulin level is mild which means that the BV enhances insulin sensitivity in the peripheral tissues which manifested as decreased HOMA-insulin resistance index in the NAFL rats treated with BV. In line with these data, in alloxan-induced type 1 diabetes, the treatment with BV for 4 weeks resulted in significant decline in the blood glucose level and increase in insulin level (35). BV treatment also completely normalized the lipid profile values of serum TG, total cholesterol, LDL-C, and HDL-C. The effect was more prominent with cholesterol, LDL-C, and HDL-C which were completely normalized even with the lowest dose. In line with these results, many studies on different health conditions support the lipotropic effect of BV treatments (36).
These biochemical data were confirmed by the histological findings. Histopathological examination of the liver of NAFL rats treated with the lower dose of $\mathrm{BV}$ revealed normal hepatocytes architecture with patent sinusoids. However, apoptotic cells with steatosis were still recognized. Increasing the dose of BV improved the impairment in the histological features to become more or less similar to normal control rats with a minimal number of steatotic figures with the highest dose. Moreover, BV treatment of NAFL rats caused a dose-dependent decline in the level of TNF- $\alpha$ in accordance with a study that documented that $\mathrm{BV}$ treatment reduces TNF- $\alpha$ levels in mice (37). Also, BV treatment showed a dose-dependent elevation of active nuclear Nrf2 compared to the untreated rats while the significant elevation was observed at the high dose. Nrf2 through the induction of the different antioxidant systems may control-normalize- redox state of the liver and the level of GSH which mediate the ameliorating effects on the NAFL rats.

The best ameliorative effect of BV was observed at the hepatic level of adiponectin (completely normalized even with the lowest dose; $0.05 \mathrm{mg} / \mathrm{kg}$ ) followed by $\mathrm{Nrf} 2$. These results lead us to suggest that, mechanistically, BV therapeutic effects against NAFL manifestations may be mediated through induction of adiponectin; the powerful insulin-sensitizing hormone, which in turn activates Nrf2 pathway through activation of AMPK. AMPK pathway is important for activation of Nrf2 pathways and for the efficient nuclear accumulation of Nrf2 protein as well to bind to its response elements in the regulatory domains of the Nrf2 targets (38), thereby activating their transcription $(39,40)$ and downregulate the expression of TNF- $\alpha$. Therefore, $\mathrm{BV}$ reduces the inflammation and the oxidative stress and induce insulin sensitivity which in turn ameliorates liver function parameters; ALT, AST, GGT and bilirubin levels and normalizing the redox state of the liver and confirmed also by histopathological examination that showed minimal hepatocytes inflammation with normal hepatocytes architecture. The previous conclusion is supported by the results of this study, which indicated that NAFL rats treated with BV showed significantly lower hepatic levels of MDA compared to untreated rats in a dose-dependent manner. The antioxidant potential of BV had been confirmed in different studies carried on different pathological conditions $(41,42)$.

The present study represents an advance in biomedical science because it shows the antioxidant potential of BV treatment and its normalization effect on adipocytokines that makes it a tempting therapeutic agent for NAFLD.

\section{Acknowledgements}

Not applicable.

\section{Funding}

No funding was received.

\section{Availability of data and materials}

The datasets used and/or analyzed during the current study are available from the corresponding author on reasonable request. 


\section{Authors' contributions}

MAK, MYH and MHH designed the study, wrote the protocol, supervised the research, managed the literature searches, and read and approved the final manuscript. AHK peformed the histological part of the study, and ELZ, SEEA, AS and AHG carried out the research work, performed the statistical analysis, and wrote the first draft of the manuscript.

\section{Ethics approval and consent to participate}

Experimental procedures, animal handling, sampling, and scarification followed the Guide for the Care and Use of Laboratory Animals, 8th edition (National Research Council, 2011) and were approved by Research Ethical Committee of the Medical Research Institute, Alexandria University. The current study adheres to the ARRIVE Guidelines for reporting animal research and a completed ARRIVE guidelines checklist is included in S1 Checklist.

\section{Consent for publication}

Not applicable.

\section{Competing interests}

The authors declare that they have no competing interests.

\section{References}

1. Neuschwander-Tetri BA and Caldwell SH: Nonalcoholic steatohepatitis: Summary of an AASLD single topic conference. Hepatology 37: 1202-1219, 2003.

2. Musso G, Cassader M, De Michieli F, Rosina F, Orlandi F and Gambino R: Nonalcoholic steatohepatitis versus steatosis: Adipose tissue insulin resistance and dysfunctional response to fat ingestion predict liver injury and altered glucose and lipoprotein metabolism. Hepatology 56: 933-942, 2012.

3. Halbleib M, Skurk T, de Luca C, von Heimburg D and Hauner H: Tissue engineering of white adipose tissue using hyaluronic acid-based scaffolds. I: In vitro differentiation of human adipocyte precursor cells on scaffolds. Biomaterials 24: 3125-3132, 2003.

4. Day CP and James OF: Steatohepatitis: A tale of two 'hits'? Gastroenterology 114: 842-845, 1998.

5. Bugianesi E, Gastaldelli A, Vanni E, Gambino R, Cassader M, Baldi S, Ponti V, Pagano G, Ferrannini E and Rizzetto M: Insulin resistance in non-diabetic patients with non-alcoholic fatty liver disease: Sites and mechanisms. Diabetologia 48: 634-642, 2005.

6. Hui JM, Hodge A, Farrell GC, Kench JG, Kriketos A and George J: Beyond insulin resistance in NASH: TNF-alpha or adiponectin? Hepatology 40: 46-54, 2004.

7. Houstis N, Rosen ED and Lander ES: Reactive oxygen species have a casual role in multiple forms of insulin resistance. Nature 440: 944-948, 2006.

8. Franco R, Schoneveld OJ, Pappa A and Panayiotidis MI: The central role of glutathione in the pathophysiology of human diseases. Arch Physiol Biochem 113: 234-258, 2007.

9. Kwak MK, Wakabayashi N, Itoh K, Motohashi H, Yamamoto M and Kensler TW: Modulation of gene expression by cancer chemopreventive dithiolethiones through the Keap1-Nrf2 pathway. Identification of novel gene clusters for cell survival. J Biol Chem 278: 8135-8145, 2003.

10. Yates MS, Tran QT, Dolan PM, Osburn WO, Shin S, McCulloch CC, Silkworth JB, Taguchi K, Yamamoto M, Williams CR, et al: Genetic versus chemoprotective activation of Nrf2 signaling: Overlapping yet distinct gene expression profiles between Keap1 knockout and triterpenoid-treated mice. Carcinogenesis 30: 1024-1031, 2009.
11. Sugimoto H, Okada K, Shoda J, Warabi E, Ishige K, Ueda T, Taguchi K, Yanagawa T, Nakahara A, Hyodo I, et al: Deletion of nuclear factor-E2-related factor-2 leads to rapid onset and progression of nutritional steatohepatitis in mice. Am J Physiol Gastrointest Liver Physiol 298: G283-G294, 2010.

12. Zhang YK, Yeager RL, Tanaka Y and Klaassen CD: Enhanced expression of Nrf2 in mice attenuates the fatty liver produced by a methionine- and choline-deficient diet. Toxicol Appl Pharmacol 245: 326-334, 2010.

13. Jang MH, Shin MC, Lim S, Han SM, Park HJ, Shin I, Lee JS, Kim KA, Kim EH and Kim CJ: Bee venom induces apoptosis and inhibits expression of cyclooxygenase-2 mRNA in human lung cancer cell line NCI-H1299. J Pharmacol Sci 91: 95-104, 2003.

14. Hong SJ, Rim GS, Yang HI, Yin CS, Koh HG, Jang MH, Kim CJ, Choe BK and Chung JH: Bee venom induces apoptosis through caspase-3 activation in synovial fibroblasts of patients with rheumatoid arthritis. Toxicon 46: 39-45, 2005.

15. Sene-Fiorese M, Duarte FO, Scarmagnani FR, Cheik NC, Manzoni MS, Nonaka KO, Rossi EA, de Oliveira Duarte AC and Dâmaso AR: Efficiency of intermittent exercise on adiposity and fatty liver in rats fed with high fat diet. Obesity (Silver Spring) 16: 2217-2222, 2008.

16. Lopes-Virella MF, Stone PG and Colwell JA: Serum high density lipoprotein in diabetic patients. Diabetologia 13: 285-291, 1977.

17. Friedewald WT, Levy RI and Fredrickson DS: Estimation of the concentration of low-density lipoprotein cholesterol in plasma, without use of the preparative ultracentrifuge. Clin Chem 18: 499-502, 1972.

18. Caumo A, Perseghin G, Brunani A and Luzi L: New insights on the simultaneous assessment of insulin sensitivity and beta-cell function with the HOMA2 method. Diabetes Care 29: 2733-2734, 2006.

19. Bligh EG and Dyer WJ: A rapid method of total lipid extraction and purification. Can J Biochem Physiol 37: 911-917, 1959.

20. Muthusamy VR, Kannan S, Sadhaasivam K, Gounder SS, Davidson CJ, Boeheme C, Hoidal JR, Wang L and Rajasekaran NS: Acute exercise stress activates Nrf2/ARE signaling and promotes antioxidant mechanisms in the myocardium. Free Radic Biol Med 52: 366-376, 2012.

21. Draper HH and Hadley M: Malondialdehyde determination as index of lipid peroxidation. Methods Enzymol 186: 421-431, 1990.

22. Griffith OW: Determination of glutathione and glutathione disulfide using glutathione reductase and 2-vinylpyridine. Anal Biochem 106: 207-212, 1980.

23. Smith IK, Vierheller TL and Thorne CA: Assay of glutathione reductase in crude tissue homogenates using 5,5'-dithiobis(2-nitrobenzoic acid). Anal Biochem 175: 408-413, 1988.

24. Habig WH, Pabst MJ and Jakoby WB: Glutathione S-transferase AA from rat liver. Arch Biochem Biophys 175: 710-716, 1976.

25. Flohé L and Günzler WA: Assays of glutathione peroxidase. Methods Enzymol 105: 114-121, 1984.

26. Tangvarasittichai S: Oxidative stress, insulin resistance, dyslipidemia and type 2 diabetes mellitus. World J Diabetes 6: 456-480, 2015.

27. Di Chiara T, Argano C, Corrao S, Scaglione R and Licata G: Hypoadiponectinemia: A link between visceral obesity and metabolic syndrome. J Nutr Metab 2012: 175245, 2012.

28. Tilg H and Moschen AR: Adipocytokines: Mediators linking adipose tissue, inflammation and immunity. Nat Rev Immunol 6: 772-783, 2006.

29. Tilg $\mathrm{H}$ and Hotamisligil GS: Nonalcoholic fatty liver disease: Cytokine-adipokine interplay and regulation of insulin resistance. Gastroenterology 131: 934-945, 2006.

30. Kono H, Rusyn I, Yin M, Gäbele E, Yamashina S, Dikalova A, Kadiiska MB, Connor HD, Mason RP, Segal BH, et al: NADPH oxidase-derived free radicals are key oxidants in alcohol-induced liver disease. J Clin Invest 106: 867-872, 2000.

31. Weltman MD, Farrell GC, Hall P, Ingelman-Sundberg M and Liddle C: Hepatic cytochrome P450 2E1 is increased in patients with nonalcoholic steatohepatitis. Hepatology 27: 128-133, 1998.

32. Shoelson SE, Herrero L and Naaz A: Obesity, inflammation, and insulin resistance. Gastroenterology 132: 2169-2180, 2007.

33. Kensler TW, Wakabayashi $\mathrm{N}$ and Biswal S: Cell survival responses to environmental stresses via the Keap1-Nrf2-ARE pathway. Annu Rev Pharmacol Toxicol 47: 89-116, 2007.

34. Lee JY, Kang SS, Kim JH, Bae CS and Choi SH: Inhibitory effect of whole bee venom in adjuvant-induced arthritis. In Vivo 19: 801-805, 2005. 
35. Mousavi SM, Imani S, Haghighi S, Mousavi SE and Karimi A Effect of Iranian honey bee (Apis mellifera) venom on blood glucose and insulin in diabetic rats. J Arthropod Borne Dis 6 : 136-143, 2012.

36. Behroozi J, Divsalar A and Saboury AA: Honey bee venom decreases the complications of diabetes by preventing hemoglobin glycation. J Molec Liquids 199: 371-375, 2014.

37. Yang EJ, Jiang JH, Lee SM, Yang SC, Hwang HS, Lee MS and Choi SM: Bee venom attenuates neuroinflammatory events and extends survival in amyotrophic lateral sclerosis models. J Neuroinflammation 7: 69, 2010.

38. Kwak MK, Wakabayashi N, Itoh K, Motohashi H, Yamamoto M and Kensler TW: Modulation of gene expression by cancer chemopreventive dithiolethiones through the Keap1-Nrf2 pathway. Identification of novel gene clusters for cell survival. J Biol Chem 278: 8135-8145, 2003.
39. Mo C, Wang L, Zhang J, Numazawa S, Tang H, Tang X, Han X, Li J, Yang M, Wang Z, et al: The crosstalk between Nrf2 and AMPK signal pathways is important for the anti-inflammatory effect of berberine in LPS-stimulated macrophages and endotoxin-shocked mice. Antioxid Redox Signal 20: 574-588, 2014.

40. Joo MS, Kim WD, Lee KY, Kim JH, Koo JH and Kim SG: AMPK facilitates nuclear accumulation of Nrf2 by phosphorylating at serine 550. Mol Cell Biol 36: 1931-1942, 2016.

41. Hwang DS, Kim SK and Bae H: Therapeutic effects of bee venom on immunological and neurological diseases review. Toxins (Basel) 7: 2413-2421, 2015.

42. Ram SKM, Jayapal N, Nanaiah P, Aswal GS, Ramnarayan BK and Taher SM: The therapeutic benefits of bee venom. Int J Curr Microbiol App Sci 3: 377-381, 2014. 